\title{
Do Microfractures Work?
}

\author{
Radu Prejbeanu1, Daniel Laurențiu Pop¹, Bogdan Cătălin Ciupe¹, Carol Sălățeanu, Andrei Dan \\ Bălănescu1', Tiberiu Bățagă²
}

1 1st Department of Orthopedics and Traumatology, "Pius Brînzeu" County Emergency Clinical Hospital, Timișoara, Romania

2 Department of Orthopedics and Traumatology, County Emergency Clinical Hospital, Tîrgu Mureș, Romania

\section{CORRESPONDENCE}

\section{Daniel Laurențiu Pop}

B-dul Liviu Rebreanu nr. 156

300723 Timișoara, Romania

Tel: +40356433111

E-mail: daniellaurentiupop@gmail.com
Radu Prejbeanu • B-dul Liviu Rebreanu nr.156 300723 Timișoara, Romania. Tel: +40 356433 111, E-mail: raduprejbeanu@gmail.com

Bogdan Cătălin Ciupe • B-dul Liviu Rebreanu nr.156 300723 Timișoara, Romania. Tel: +40 356433 111, E-mail: ciupebogdan@yahoo.ro

Carol Sălățeanu • B-dul Liviu Rebreanu nr.156 300723 Timișoara, Romania. Tel: +40 356433 111, E-mail: salateanucarol@gmail.com

Andrei Dan Bălănescu • B-dul Liviu Rebreanu nr.156 300723 Timișoara, Romania. Tel: +40 356433 111, E-mail: andreidan.balanescu@gmail.com

Tiberiu Bățagă • Str. Gheorghe Marinescu nr. 38 540139 Tîrgu Mureș, Romania. Tel: +40 265215 551, E-mail: tbataga@gmail.com

\begin{abstract}
It has been observed that injuries, which involve only a part of the joint cartilage thickness, show a partial healing ability, but some healing potential is present in the case of injuries that affect the subchondral osseous tissue. The methods of treatment for chondral defects are nonsurgical: pharmacological chondroprotection (nutraceuticals containing chondroitin sulphate and glucosamine sulphate), viscosupplementation, PRP and cytokine modulation. The surgical options include palliative approaches, marrow stimulation, and cell-based regeneration techniques. The microfracturing technique has started to be used in the ' 80 s using equine models. The basic principle of microfracturing is to stimulate cartilage repair, not regeneration. It represents the first line of therapy for cartilage defects that affect its full thickness. The advantages of microfracturing are: it is a minimally invasive procedure, technical simplicity, decreased surgical morbidity, and low costs, thus making it a common procedure. However, microfracturing is not a bulletproof technique. There is a high rate of treatment failure after 5 years. Constant decline of the outcome during the 5-year follow-up after surgery is also described. Lesion size represents a better predictor regarding outcome, compared to age. The best results are obtained in young patients, small lesions and low-demand patients. Microfractures can be augmented using BMAC (bone marrow aspirate concentrate) containing $0-0.1 \%$ progenitor cells. The matrix aids in the improvement of microfractures, and it also increases the stability of the blood clot, acting as a barrier that avoids the fibroblast invasion of the graft. There is still a place for microfractures in chondral defects. Better results can be achieved with an improved technique, an optimized rehabilitation, and adding several augmentation techniques.
\end{abstract}

Keywords: chondral defect, microfracture, knee cartilage

\section{INTRODUCTION}

In 1743 William Hunter observed that injuries that involve only a part of the joint cartilage thickness show a partial healing ability, but some healing potential is present for injuries that affect the subchondral osseous tissue.

A total of 25,124 knee arthroscopies have shown injured cartilage in 15,074 knees $(60 \%)$, and around $67 \%$ have been categorized as focal damage. Approximately $5-10 \%$ of them were focal and frequently asymptomatic injuries. ${ }^{1}$

The methods of treatment for chondral defects are nonsurgical: pharmacological chondroprotection (nutraceuticals containing chondroitin sulphate and glucosamine sulphate), viscosupplementation, PRP and cytokine modulation. 

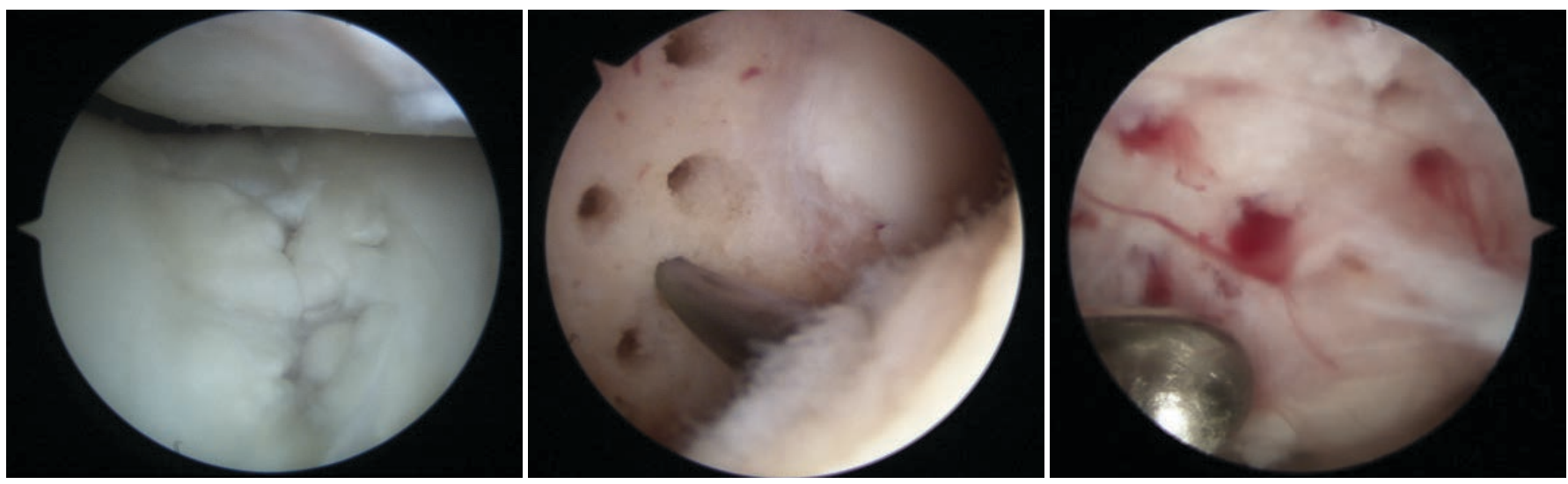

FIGURE 1. The microfracture technique for the treatment of articular cartilage lesions in the knee (from the photo archive of the 1 st Department of Orthopedics and Traumatology, "Pius Brînzeu" Clinical Hospital, Timișoara, Romania). A - Chondral defect. B - Microfracture holes. C - Bleeding via drilling holes.

Surgical options include palliative approaches, marrow stimulation, and cell-based regeneration techniques. The Pridie drilling for osteoarthritis was introduced in 1959, and it was used as a marrow stimulation technique by subchondral drilling. ${ }^{2}$

\section{MICROFRACTURES - OLD AND UP-TO-DATE TECHNIQUE}

The microfracturing technique has started to be used in the '80s using equine models. ${ }^{3}$ Its principle is to stimulate repair, not regeneration. It represents the first line of therapy for cartilage defects that affect its full thickness. The advantages of microfractures are: it is a minimally invasive procedure, technical simplicity, decreased surgical morbidity, and low costs, thus making it a common procedure.

A correct approach to microfracturing is taking into account the patient's history, the clinical examination, the result of the MRI assessment, the available equipment (the area, size and location of the defect require an array of tools), costs, and the patient's option. When examining the subchondral edema, one can observe areas of marrow edema with abnormal perfusion, and a decreased number of progenitor cells. ${ }^{4}$

The microfracture method is indicated for acute, fullthickness and well-defined chondral injuries. An inevitable bad result often occurs in case of microfracture procedures when it comes to approaching large defects, pre-existing malalignment, primary or secondary instability or osteochondritis dissecans.

Microfractures have no indication in case of existing malalignment, partial thickness injuries, kissing lesions, and age over 50 years. In order to achieve good results, several aspects should be carefully considered: the lesions should be smaller than $2 \mathrm{~cm}$, the injury should be new, only contained lesions should be included, the patient should be younger than 35 years and the BMI lower than 30 .

From a technical standpoint, the drilled holes should be at 3-4 $\mathrm{mm}$, with a depth of $2-4 \mathrm{~mm}$. New recommendations state that the surgeon should drill as many holes as possible, without creating macrofractures, and the drilling should be deep enough to create bleeding. The rough surface thus created, holds the marrow clot. ${ }^{5}$

\section{HISTOLOGICAL ASPECTS}

The cells in the clot, which are non-differentiated mesenchymal cells, will mature to create a fibrocartilage repair tissue with type II collagen that has lower rigidity and lower wear compared to that of the typical hyaline chondroma. ${ }^{5}$

Drilling and microfracturing stimulate the proliferation of a different osseous structure and necrosis compared to the one that occurs during bone-marrow stimulation for cartilage repair. ${ }^{6}$

The adverse effect of the microfracturing procedure is fractured and compacted bone around the drilled holes. This phenomenon creates a barrier for viable bone marrow that can hinder the repair process. Therefore, a different approach should be considered. On the other hand, drilling removes bone, thus creating a clean route for the bone marrow. ${ }^{6}$

In the first 2 years following the procedure, there is a 75-100\% improvement rate, decreasing after 2 years to $67-86 \%$. Functional deterioration is $47-80 \%$. The improvement rate after 10 years is over baseline.7,8

MRI performed after the microfracturing procedure shows a complete fill in $18-95 \%$ of cases, and a poor fill 
is described in $17-57 \%$ of cases. A complete integration is observed in $4-8 \%$ of cases. The function correlates with the fill. $8,9,10$

Microfracturing is not a bulletproof technique. There is a high rate of treatment failure after 5 years. Constant decline of the outcome during the 5-year follow-up after surgery is also described. Lesion size represents a better predictor regarding outcome, compared to age. The best results are obtained in young patients, small lesions and low-demand patients. ${ }^{11,12}$

\section{MICROFRACTURING FAILURE}

Revision or failure at $<2$ years is around $2.5 \%$, and between $2-10$ years it is $2-38 \%$.

An increased failure rate with lower repair tissue quality and a longer duration of symptoms is approximately $48 \%$ Kellgren I at 10 years. $7,8,13$

The chance of failure increases as the incidence of the following factors is higher: age over 40 years, duration of symptoms over 12 months, lesion's size larger than $4 \mathrm{~cm}$, BMI above 30, preoperative activity level as classified using the Tegner Score lower than 4, a defect fill greater that two thirds of the original injury. ${ }^{8}$

Subchondral hypertrophy is found in $46 \%$ of patients one year after surgery and up to $62 \%$ around 22 months after surgery. A higher BMI, an injury located in the external compartment of the knee, and the choice of surgical technique is associated with a higher prevalence of subchondral hypertrophy.

\section{AUGMENTATION CONCEPT}

The augmentation process is performed using BMAC (bone marrow aspirate concentrate) containing $0-0.1 \%$ progenitor cells. The matrix aids in the improvement of microfractures, and it also increases the stability of the blood clot, acting as a barrier that avoids the fibroblast invasion of the graft. This method extends the applicability of microfractures from small to medium-sized cartilage defects.

\section{CONCLUSIONS}

Recent results show that there is still a place for microfractures in injuries that affect the full thickness of the cartilage. Practitioners must take into account the reasons of failure, and try to minimize them as much as possible. Improving the outcomes can be achieved with a better technique, an optimized rehabilitation, and augmentation techniques. There is still room for improvement in this field of injuries, and prospective randomized trials can yield objective results.

\section{CONFLICT OF INTEREST}

The authors have nothing to declare.

\section{REFERENCES}

1. Widuchowski W, Widuchowski J, Trzaska T. Articular cartilage defects: study of 25,124 knee arthroscopies. Knee. 2007;14:177-182.

2. Pridie $\mathrm{KH}$. A method of resurfacing osteoarthritic knee joints. Journal of Bone and Joint Surgery. 1959;41:618-619.

3. Steadman JR, Rodkey WG, Briggs KK, Rodrigo JJ. The microfracture technic in the management of complete cartilage defects in the knee joint. Orthopäde. 1999;28:26-32.

4. Steadman JR, Rodkey WG, Briggs KK. Microfracture: Its History and Experience of the Developing Surgeon. Cartilage. 2010;1:78-86.

5. Hongmei C, Sun J, Hoemann CD, Lascau-Coman V, et al. Drilling and microfracture lead to different bone structure and necrosis during bonemarrow stimulation for cartilage repair. J Orthop Res. 2009;27:1432-1438.

6. Gudas R, Gudaite A, Pocius A, et al. Ten-year follow-up of a prospective, randomized clinical study of mosaic osteochondral autologous transplantation versus microfracture for the treatment of osteochondral defects in the knee joint of athletes. Am J Sports Med. 2012;40:2499-2508.

7. Mithoefer K, McAdams T, Williams RJ, Kreuz PC, Mandelbaum BR. Clinical efficacy of the microfracture technique for articular cartilage repair in the knee: an evidence-based systematic analysis. Am J Sports Med. 2009;37:2053-2063.

8. Mithoefer K, Williams RJ, Warren RF, The microfracture technique for the treatment of articular cartilage lesions in the knee. A prospective cohort study. J Bone Joint Surg Am. 2005;87:1911-1920.

9. Ramappa AJ, Gill TJ, Bradford CH, Ho CP, Steadman JR. Ramappa AJ Magnetic resonance imaging to assess knee cartilage repair tissue after microfracture of chondral defects. J Knee Surg. 2007;20:228-234

10. Goyal D, Keyhani S, Lee EH, Hui JH. Evidence-based status of microfracture technique: a systematic review of level I and II studies. Arthroscopy. 2013;29:1579-1588.

11. Salzmann GM, Sah B, Südkamp NP, Niemeyer P. Reoperative characteristics after microfracture of knee cartilage lesions in 454 patients. Knee Surg Sports Traumatol Arthrosc. 2013;21:365-371.

12. Mithoefer K, Venugopal V, Manaqibwala M. Incidence, Degree, and Clinical Effect of Subchondral Bone Overgrowth After Microfracture in the Knee. Am J Sports Med. 2016;44:2057-2063.

13. Anders S, Volz M, Frick H, Gellissen J. A Randomized, Controlled Trial Comparing Autologous Matrix-Induced Chondrogenesis $\left(\mathrm{AMIC}^{\circledR}\right)$ to Microfracture: Analysis of 1- and 2-Year Follow-Up Data of 2 Centers. Open Orthop J. 2013;7:133-143. 